Almost all the other papers dealt with practicetechnology and measurements-or with the properties of junctions. In the main they consolidated or clarified earlier work, or directed more detailed atten. tion to outstanding problems; some contained comprehensive measurements. Only a few of the many points made can be reviewed here.

Improved trace-analysis has been needed to assist the purification of silicon. The common donor elements can now be estimated to 1 part in $10^{\prime}$ by methods using radioactivation; equally sensitive methods are still lacking, however, for two acceptor elements, boron and aluminium. The rates of evaporation of donor and acceptor elements from molten silicon have been measured; when proper attention is paid to them, as well as to segregation constants, control of resistivity of single crystals grown from the melt is much improved. Carrier life-time in silicon is markedly dependent on injection-level; values for very low levels, obtained in part by extrapolation, have enabled a study of dependence on temperature to be commenced.

It has been suggested that most of the carriers responsible for the reverse current of a $p$ - $n$ junction in silicon are generated, not in the $n$ - or $p$-regions, but in the depletion layer. New measurements, showing the current to have an activation energy of only $0.7 \mathrm{eV}$., point to the current arising in a surface channel. An analysis of a model of a $p \cdot n$ rectifier, intermediate between the one-junction ( $p$ - $n$-ohmic) and two-junction $\left(p-n-n^{t}\right)$ models, was presented; it, too, predicted a two-component forward currentvoltage relationship, $I \propto \exp (q V \mid k T)$ at small voltages and $I \propto \exp (q V / 2 K T)$ at large voltages.

The non-ohmic conductivity of $n$-type germanium has been measured for fields less than, as well as greater than, $10^{3} \mathrm{~V} . / \mathrm{cm}$. For fields between $10^{4}$ and $6 \times 10^{4} \mathrm{~V} . / \mathrm{cm}$. it is so pronounced that the electron drift-velocity changes very little; thereafter avalanche multiplication sets in. Many of the properties of small-area diodes can be explained by these phenomena alone.

There were contributions on noise -an endeavour to detect shot-noise-surface conduction and the Ettingshausen effect, all in germanium.

Compound semiconductors also received attention. Extensive measurements were reported for indium antimonide and indium arsenide-for both of which some degeneracy remained at all temperatures even in the purest samples-and for gallium arsenide of improved purity, many donors having been removed by zone-refining. Measurements of photo-effects in indium antimonide were used to deduce carrier mobilities, $\mu_{e}$ and $\mu_{h}$, and life-time. There was marked dependence of $\mu_{e}$ on hole-concentration in $p$ material ; life-times were short, less than 0.1 microsec., at room temperature. The spectrum of recombination radiation from indium antimonide has now been measured; because the absorption spectrum of thin specimens enables a value of radiation life-time of about 0.8 microsec. to be deduced, which is little more than some experimental values of carrier lifetime, it was concluded that recombination in indium antimonide may be mainly radiative.

The electron contribution to the thermal conductivity, at room temperature, of an impure sample of indium antimonide (Hall constant $2 \times 10^{-4} \mathrm{~cm}^{3} /$ coulomb) was calculated to account for the observed increase above the value for a purer sample $\left(5 \times 10^{-3}\right.$ cm. ${ }^{3}$ /coulomb). However, whereas the electronic contribution in extrinsic bismuth telluride conformed with existing theory, the contribution in intrinsic material was more than expected, probably due to the transfer of ionization energy down a thermal gradient.

The nuclear resonance of indium-115 in highly degenerate $n$-type indium antimonide was shown not to differ in frequency from that in intrinsic material (that is, the Knight shift was absent) ; an adequate explanation lies in the very small effective mass of conduction-electrons in indium antimonide. The size and shape of the resonance are sensitive to cold working of the crystals and to the addition of tellurium as a donor.

The many informal discussions, possible because the audience was in residence, continually stressed the need for more frequent, similar, meetings. The subject has entered so many fields of science and technology, and so quickly finds new applications of effects, that the workers in the field, many of them young, have difficulty in keeping themselves adequately informed.

J. R. TilrmaN

\section{THE WHISTLED LANGUAGE OF LA GOMERA}

T A GOMERA is one of the Canary Islands, lying 1 in the Atlantic off the west coast of North Africa. It is inhabited by some 30,000 Spanish-speaking people, scattered over the island in many tiny hamlets and four little towns. The island, volcanic in origin, is distinguished by a rugged and peculiar topography. It has the general shape of a big tent ; from a central peak some 4,500 ft. high it slopes down on all sides to sheer cliffs at the sea's edge. Deep gorges radiating from the centre cut up the terrain. It is a difficult, mountainous country where two points only 500 yards apart as the crow flies may be as much as an hour apart in walking time. Apart from a single road, which links San Sebastian, the capital, with the other three towns, the only means of travel between most points on the island is by rough paths which are little better than goat tracks; communication on the island is a great problem.

But the Gomeros do communicate freely, across their ravines and from the valleys to the mountaintops. The method of communication has been described in an article by André Classe (Sci. Amer., 196, No. 5; May 1957). Long ago the Gomeros contrived an elegant solution to their problem : namely, a whistled language by which they speak to each other across miles of disjoined terrain. The silbo, as this language is called, is not a mere code or signal system but a version of Spanish. It has extraordinary carrying power: it can be heard and understood clearly over far greater distances than shouted talk. On a windless day any practised silbador can be heard more than a mile away. A good performer can whistle messages three miles or more.

On La Gomera, goatherds on widely separated hills carry on silbo conversations merely to pass the time. They whistle long sentences and even make jokes. During the Spanish Civil War in 1936-39 Gomeros were used occasionally for communication at the front; but the practice was discontinued when it was discovered that there were silbadores on both sides, so that the degree of secrecy was not high. 
This curious medium of communication owes its existence to the geography of La Gomera. It goes back to the aborigines who inhabited it before the Spanish arrived in the fifteenth century. The aboriginal residents in the Canary Islands, called the Guanches, had developed a whistled form of their language for communication in their territory, then so thickly wooded that whistles were the only kind of 'talk' which could be transmitted for any distance.

The silbo is based directly on the Spanish language and is learned effortlessly and as a matter of course by most Gomeros. Children on La Gomera pick up silbo as naturally as they pick up spoken Spanish in their parents' talk; they often begin to recognize their own name in silbo before they are a year old.

The fact that the whistled language depends only on pitch explains why it can be understood at much greater distances than ordinary shouted speech. The sounds of ordinary speech are complex waves containing a number of harmonics. What makes such speech unintelligible at a distance is the loss of the weak harmonics and transients. On the other hand, a whistled signal, the meaning of which does not depend on timbre but is determined solely by pitch, will be understood perfectly so long as it is heard at all.

How does the silbo, using only variations in the pitch of a whistle, express the sounds of Spanish ? It is fortunate that the language is Spanish; it would be vastly more difficult to whistle English, for English has a complex phonetic system. The Spanish phonetic system, especially in the Gomero dialect, is almost the simplest possible : it has comparatively few different vowel and consonant sounds, and relatively little contribution to meaning is made by stress, rhythm or intonation. All the silbador has to do is put the tip of his tongue against his teeth, start whistling and, at the same time, try to articulate words as if he were speaking normally. A practised silbador can whistle intelligibly everything he can say in the Spanish language. The whistle does not differentiate all the consonants in the spoken language, but when the silbador whistles words and sentences, the context makes his meaning unambiguous. Like ordinary speech, the silbo is differentiated into dialects and even individual styles. Each silbador has his own delivery.

Nothing better illustrates how commonly the Gomeros use the silbo than an experience Classe had one day in the wilds of the middle of the island. He was climbing the central mountain and all around in the woods were blackbirds whistling, not their own bird songs but, unmistakably and with excellent articulation, the silbo for the names 'Felipe', 'Alfonso', 'Frederico' and so on. In each case the bird prefixed the name with the attention-calling sound 'ah', which invariably precedes a call in the silbo.

The silbo of La Gomera is by no means the only whistled language in the world; but it is the most explicit. Other whistled forms of communication, found in Mexico and some parts of Africa, are made up of the tones, isolated from the other elements of speech, and convey meaning by a kind of musical accent. Generally speaking these other whistled languages are far less accurate, less explicit and more limited in power of expression than the silbo. The silbo is of great interest to a linguist because it does without what is commonly thought to be the one indispensable feature of normal speech: namely, variation of tone quality.

\section{PASSIVATION OF IRON BY CHROMATE SOLUTIONS}

$\mathrm{E}^{\mathrm{s}}$ TIMATIONS, in this Laboratory ${ }^{2}$ and elsewhere ${ }^{2}$, of the amount of chromium in the protective films formed on iron during immersion in potassium chromate solution have been reported. Further measurements in this Laboratory, using the radioactive tracer technique previously reported ${ }^{1}$, have yielded results apparently of considerable theoretical interest. Publication of these results (apart from summaries in "Chemistry Research"') has been delayed because of some uncertainty con. cerning the effect of the method of preparation of the radioactive potassium chromate solution (labelled with chromium-51) on the absolute figures for uptake of chromium, though it has been apparent for some time that the figures obtained have given useful relative results. (It is desirable to record here that slow precipitation of trivalent chromium in some earlier solutions ${ }^{1}$ led to an incorrect conclusion concerning the effect of concentration of chromate on uptake of chromium; the concentration now appears to have little effect on uptake.) In view of the wide interest in the mechanism of corrosion inhibition, passivity and film growth at room temperatures, it now seems opportune to publish an abbreviated account of some of these results.

A family of curves has been obtained (Fig. 1) by plotting uptake of chromium against $\log _{10}\left(t_{s}+1\right)$ (where $t_{s}$ is time of immersion in chromate), for various times of pre-exposure of the specimens to air $\left(t_{a}\right)$ before immersion. The nature of this family of curves has been interpreted as follows. The curve for the relatively short time $t_{a}=5 \mathrm{~min}$. shows that uptake of chromium is a linear function of the logarithm of time. If it is reasonably assumed that the chromium, which has been detected only as $\mathrm{Cr}^{3+}$ (presumably in the form of $\mathrm{Cr}_{2} \mathrm{O}_{3}$ ), constitutes a constant proportion of the growing film, this relationship with time also applies to the film growth. The remainder of the curves ( $t_{\alpha}$ greater than 5 min.) show the same 'logarithmic' film growth in chromate solution, but are displaced downwards because growth of the oxide film had already started in air before immersion of the specimen in the chromate solution; a straight line plot of growth v. $\log$ (time) can only be obtained if both growth increments and time are measured from the moment of start of growth. It can readily be shown that uptake curves for chromium ( $t_{a}$ not negligible) should, starting from a common origin, become parallel to the original straight line $\left(t_{a}\right.$ negligible), when $t_{s}$ is very much larger than $t_{a}$, and that, further, this parallel portion will be displaced downwards by an amount proportional to the growth already present at the new starting point. It has, in fact, been found that this downward displacement is proportional to $\log _{10}\left(t_{a}+1\right)$ for the various curves, 